\title{
Inhibitory effect and mechanism of action (MOA) of hirsutine on the proliferation of T-cell leukemia Jurkat Clone E6-1 cells
}

\author{
Jie Meng ${ }^{1,2}$, Rui Su ${ }^{1}$, Luping Wang ${ }^{1}$, Bo Yuan ${ }^{\text {Corresp., } 1}$, Ling Li ${ }^{\text {Corresp. } 1}$ \\ ${ }^{1}$ Department of Pharmacy, Tongren Hospital, Shanghai Jiaotong University School of Medicine, Shanghai, 200336, China \\ 2 Hongqiao International Institute of Medicine, Shanghai Jiaotong University School of Medicine, Shanghai, 200336, China \\ Corresponding Authors: Bo Yuan, Ling Li \\ Email address: YB2718@shtrhospital.com, LL2699@shtrhospital.com
}

\begin{abstract}
Background. The bark of Uncaria rhynchophylla has been traditionally used to treat convulsion, bleeding, hypertension, auto-immune conditions, cancer, and other diseases. The main focus of this research is done for the purpose of exploring the antitumor activity and mechanism of action (MOA) for hirsutine isolated from Uncaria rhynchophylla.

Methods. Jurkat clone E6-1 cells were treated using 10, 25 and $50 \mu \mathrm{M}$ for $48 \mathrm{hrs}$. Inhibition of cell proliferation due to hirsutine treatment was evaluated by CCK8 assay. Flow cytometry was applied to ascertain Jurkat cell cycle progression and apoptosis after treatment with 10, 25 and $50 \mu \mathrm{M}$ hirsutine for $48 \mathrm{hrs}$. The expression and level of the apoptosis-related genes and proteins was analysed by Real-time Quantitative polymerase chain reaction (qPCR) and Western blotting method, respectively.
\end{abstract}

Results. CCK8 analyses revealed that hirsutine could significantly inhibit the proliferation of Jurkat clone E6-1 cells, in a concentration and time-dependent fashion. Flow cytometry assays revealed that hirsutine could drive apoptotic death and G0/G1 phase arrest in Jurkat cells. Apoptotic cells frequencies were $4.99 \pm 0.51 \%, 13.69 \pm 2.00 \%$ and $40.21 \pm 15.19 \%$, and respective cell cycle arrest in G0/G1 accounted for $34.85 \pm 1.81 \%, 42.83 \pm 0.70 \%$ and $49.12 \pm 4.07 \%$. Simultaneously, compared with the control group, western blot assays indicated that the up-regulation of pro-apoptotic Bax, cleaved-caspase3, cleavedcaspase 9 and Cyto c proteins, as well as the down-regulation of $\mathrm{Bcl}-2$ protein which guards against cell death, might be correlated with cell death induction and inhibition of cell proliferation. QPCR analyses indicated that hirsutine could diminish BCL2 expression and, at the same time, improve Bax, caspase-3 and caspase- 9 mRNA levels, thus reiterating a putative correlation of hirsutine treatment in vitro with apoptosis induction and inhibition of cell proliferation ( $p$-value $<0.05$ ). Excessive hirsutine damages the ultrastructure in mitochondria, leading to the release of Cyt c from the mitochondria to cytoplasm in Jurkat clone E6-1 cells; thereby, activated caspases cascade apoptosis process through a mitochondriamediated pathway. Conclusion. An important bioactive constituent - hirsutine - appears to have antitumor effects in human T-cell leukemia, thus enlightening the use of phytomedicines as a novel source for tumor therapy. It is speculated that hirsutine may induce apoptosis of Jurkat Clone E6-1 cells through the mitochondrial apoptotic pathway. 
1 Inhibitory effect of hirsutine on the proliferation of T-cell leukemia Jurkat 2 Clone E6-1 cells

3

4

Jie Meng ${ }^{1,2}$, Rui Su${ }^{1}$, Luping Wang ${ }^{1}$, Bo Yuan ${ }^{1 *}$, Ling $\mathrm{Li}^{1 *}$

${ }^{1}$ Tongren Hospital, Shanghai Jiaotong University School of Medicine, 200336, Shanghai, China

${ }^{2}$ Hongqiao International Institute of Medicine, Shanghai Jiaotong University School of Medicine, 200336, Shanghai, China

Corresponding Author:

Li Ling

Yuan Bo

Tongren Hospital, Shanghai Jiaotong University School of Medicine, 1111 Xianxia Road, Shanghai 200336

Email address: LL2699@shtrhospital.com

YB2718@shtrhospital.com

\section{Abstract}

Background. The bark of Uncaria rhynchophylla has been traditionally used to treat convulsion, bleeding, hypertension, auto-immune conditions, cancer, and other diseases. The main focus of this research is done for the purpose of exploring the antitumor activity and mechanism of action (MOA) for hirsutine isolated from Uncaria rhynchophylla.

Methods. Jurkat clone E6-1 cells were treated using 10, 25 and $50 \mu \mathrm{M}$ for 48 hrs. Inhibition of cell proliferation due to hirsutine treatment was evaluated by CCK 8 assay. Flow cytometry was applied to ascertain Jurkat cell cycle progression and apoptosis after treatment with 10, 25 and 50 $\mu \mathrm{M}$ hirsutine for $48 \mathrm{hrs}$. The expression and level of the apoptosis-related genes and proteins was analysed by Real-time Quantitative polymerase chain reaction (qPCR) and Western blotting method, respectively.

Results. CCK8 analyses revealed that hirsutine could significantly inhibit the proliferation of Jurkat clone E6-1 cells, in a concentration and time-dependent fashion. Flow cytometry assays revealed that hirsutine could drive apoptotic death and G0/G1 phase arrest in Jurkat cells. Apoptotic cells frequencies were $4.99 \pm 0.51 \%, 13.69 \pm 2.00 \%$ and $40.21 \pm 15.19 \%$, and respective cell cycle arrest in $\mathrm{G} 0 / \mathrm{G} 1$ accounted for $34.85 \pm 1.81 \%, 42.83 \pm 0.70 \%$ and $49.12 \pm 4.07 \%$. Simultaneously, compared with the control group, western blot assays indicated that the upregulation of pro-apoptotic Bax, cleaved-caspase3, cleaved-caspase9 and Cyto c proteins, as well as the down-regulation of Bcl-2 protein which guards against cell death, might be correlated with cell death induction and inhibition of cell proliferation. QPCR analyses indicated that hirsutine could diminish $B C L 2$ expression and, at the same time, improve Bax, caspase- 3 and caspase- 9 mRNA levels, thus reiterating a putative correlation of hirsutine treatment in vitro with apoptosis induction and inhibition of cell proliferation $(p$-value $<0.05)$. Excessive hirsutine damages the 
40 ultrastructure in mitochondria, leading to the release of Cyt $\mathrm{c}$ from the mitochondria to

41 cytoplasm in Jurkat clone E6-1 cells; thereby, activated caspases cascade apoptosis process

42 through a mitochondria-mediated pathway.

43 Conclusion. An important bioactive constituent - hirsutine - appears to have antitumor effects in 44 human T-cell leukemia, thus enlightening the use of phytomedicines as a novel source for tumor 45 therapy. It is speculated that hirsutine may induce apoptosis of Jurkat Clone E6-1 cells through 46 the mitochondrial apoptotic pathway.

47 Keywords : Hirsutine, Jurkat Clone E6-1 cells, Apoptosis, Cell cycle, Western blotting, QPCR

48

49

50

51

52

53

54

55

56

57

58

59

60

61

62

63

64

65

66

67

68

69

70

71

72

73

74

75

76

77

78

\section{Introduction}

In the past few decades, human T-cell leukemia has become a commonly found malignancy in humans (Bray et al. 2018; Miller et al. 2019). Currently, human T-cell leukemia is not only an important cause of cancer-related mortality in third world countries, but among the major factors of death in developed countries. The burden of human T-cell leukemia in developing countries have been increasing not only due to population growth and ageing, but also due to the lack of exercise, smoking and unhealthy lifestyle (Child et al. 2019; Foerster et al. 2018; Nunez et al. 2018; Yancik \& Ries 2004). Fortunately, a number of treatments, including surgery (Li et al. 2019), radiotherapy (Mondini et al. 2020), chemotherapy (Almodovar et al. 2019), and traditional Chinese medicine therapy (Hung et al. 2017), have been successful to relieve the pain and prolong the life expectancy of patients affected by T-cell leukemia.

Chemicals extracted from some plants are an important source of research into innovative cancer treatments. They have the potential to be highly effective and not overly toxic like other chemicals (Crowell 2005), and many of the chemicals in plants are already being used in health care to help develop new drugs (Chirumbolo 2012; Uramova et al. 2018). Hirsutine (Figure 1) is an indole alkaloid, originally isolated from Uncaria rhynchophylla, that has attracted attention on accounts of its biological characteristics in many aspects, like cardioprotective, antihypertensive and antiarrhythmic activities (Wu et al. 2011; Zhu et al. 2015).

Hirsutine, as a natural drug with less side effects and low toxicity, can be used in many diseases (Horie et al. 1992; Jung et al. 2013; Lou et al. 2014; Zhang et al. 2018; Zhu et al. 2015). There are now a number of trials showing that hirsutine could be applied as a common drug, besides, it also showed excellent anti-cancer effects in many cell models. Hirsutine is capable of inducing apoptosis inhibition of the HER2, NF- $\kappa$ B and Akt pathways and p38 MAPK cascade activation in several human breast cancer cell lines and appears to be linked with hirsutineinduced DNA damage and apoptosis (Lou et al. 2015). It is known that human breast cancer cells treated with hirsutine (i.e. MDA/MB-231) are prone to release mitochondrial cytochrome c and reduce mitochondrial membrane potential (MMP), thus leading to cell apoptosis (Huang et al. 2018). Furthermore, hirsutine has been said to potentially inhibits the metastatic features of 4T1 breast cancer cells both in vitro and in vivo by abrogating NF- $\mathrm{B}$ signaling (Lou et al. 2014). 
79

80

81

82

83

84

85

86

87

88

89

90

91

92

93

94

95

96

97

98

99

100

101

102

103

104

105

106

107

108

109

110

111

112

113

114

115

116

117

However, the effects of hirsutine towards apoptosis induction of T-cell leukemia Jurkat cells, and the underlying mechanisms, remain to be elucidated.

Our present work aims to clarify the antiproliferative effects of hirsutine in different human cancer cell lines. Its mechanism of action was particularly evaluated in leukemia cancer cell line Jurkat Clone E6-1. In this sense, we assessed the function of caspase activation signaling in controlling the mitochondrial-mediated apoptosis. Thus, we found that hirsutine is capable of inducing mitochondrial apoptosis in Jurkat Clone E6-1 cells. Our research provides novel insights into hirsutine-mediated apoptosis and, moreover, indicates that hirsutine may function as a valuable chemotherapy compound for treating human T-cell leukemia.

\section{Materials \& Methods}

\section{Cell lines, kits and reagents}

Jurkat Clone E6 cells were from the American Type Culture Collection (ATCC, VA, USA). Control THLE-2 hepatocytes and tubular epithelial HK2 cells from humans were collected from the Cell Resource Center of Shanghai Institutes for Biological Sciences, Chinese Academy of Sciences (Shanghai, China). RPMI-1640 medium and FBS were introduced from Hyclone Company (Cramlington, Northumberland, UK). Hirsutine (ST17300105, 5 mg/dose, purity $\geqslant$ 98\%) was purchased from Shanghai Shidande Biotechnology Company (Shanghai, China). CCK8 kit, AnnexinV-FITC apoptosis detection kit, ECL chemiluminescence kit, RIPA Lysis Buffer and BCA protein assay kit were from Shanghai Beyotime Biotech (Shanghai, China). Cytoplasmic protein extraction kit was purchased from Invitrogen (CA, USA). Antibodies against $\beta$-actin (BM0627) was purchased from BOSTER Biological Technology (Wuhan, China). Antibodies against Bcl-2 (12789-1-AP), Bax (50599-2-Ig) were from Proteintech Group (Wuhan, China), cleaved-caspase 3 (Ab32042), Cyto C (Ab133504) were from abcam (Shanghai, China), cleaved-caspase9 (AF5240) was from Affinity (Shanghai, China). Other reagents were analytical reagent grade and from commercial sources.

\section{Cell culture}

Human Jurkat Clone E6-1 cells were grown in RPMI-1640 containing 10\% FBS and penicillin/streptomycin in a $5 \% \mathrm{CO}_{2}$ humidified incubator at $37{ }^{\circ} \mathrm{C}$. Cells at $80 \%$ confluency were treated accordingly with hirsutine at different concentrations.

\section{Preparation of hirsutine solution}

Hirsutine was dissolved in DMSO at the concentration of $100 \mathrm{mM}$ and kept at $-20{ }^{\circ} \mathrm{C}$. The stock was diluted with RPMI-1640 medium to 10,25 and $50 \mu \mathrm{M}$, respectively. Final DMSO concentration in working solution was kept at $0.1 \%$. RPMI-1640 containing $0.1 \%$ DMSO was utilized for the untreated cell group. 
118 Cell viability analysis

119

120

121

122

123

124

125

126

127

128

129

130

131

132

133

134

135

136

137

138

139

140

141

142

143

144

145

146

147

148

149

150

151

152

153

154

155

156

Jurkat Clone E6-1 Cells were loaded into 96-well plate (10,000 cells/well) for $24 \mathrm{hrs}$. Thereafter, cells were treated or not with different hirsutine concentrations $(10,25$ and $50 \mu \mathrm{M})$ for $48 \mathrm{hrs}$. Alternatively, plated cells were treated using increasing amounts of hirsutine (3.9, 4.7, $9.4,18.8,37.5,75,150$ and $300 \mu \mathrm{M}$ ) for 24,48 and $72 \mathrm{hrs}$. Normal human THLE-2 hepatocytes and normal human tubular epithelial cells HK2 were loaded into 96-well plate at 4,000 cells per well. Thereafter, normal human THLE-2 hepatocytes and normal human tubular epithelial cells HK2 were treated with different concentrations of hirsutine $(15.625,31.25,62.5,125 \mu \mathrm{M})$ for 48 hours. Afterwards, $10 \mu \mathrm{L}$ of CCK 8 reagent was dripped into per well, then preserving it in an incubator at $37{ }^{\circ} \mathrm{C}$ for extra $4 \mathrm{hrs}$. Spectrophometric measurement (absorbance at $450 \mathrm{~nm}$ ) was then accessed per each well. Three replicates were analyzed for each cell treatment.

\section{Apoptosis detection by flow cytometry}

Jurkat Clone E6-1 cells at logarithmic phase were plated into 6-well dishes at $1 \times 10^{5}$ cells/well for $24 \mathrm{hrs}$. Subsequently, cells were treated with increasing amounts of hirsutine (10, 25 and $50 \mu \mathrm{M}$ ) or $0.1 \%$ DMSO (negative control). Three biological replicates were assayed per condition. Cells were further collected and rinsed once with pre-cooled PBS. After cell resuspension using pre-cooled binding buffer, AnnexinV-FITC was added, gently mixed with cell suspension and incubated at room temperature for 15 mins. Cells were then collected by centrifugation at 1,500 rpm for 5 mins and, after discarding supernatant, cells were again resuspended in pre-cooled binding buffer. Thereafter, PI staining solution was added, mixed gently with cell suspension, and stored at $4{ }^{\circ} \mathrm{C}$ in the dark. Cells were immediately analyzed by flow cytometry (Becton, Dickinson and Company).

\section{Cell cycle distribution}

Cells at the logarithmic proliferation period were plated into 6 -well dish with $10^{6}$ cells/well for $48 \mathrm{~h}$, and then distinct dosages of hirsutine were added in for another 48 hours. Cells were then centrifuged at 1,000 rpm for 5 mins. Precipitated cells were rinsed two times with cold PBS prior to fixation using $75 \%$ ethanol at $4{ }^{\circ} \mathrm{C}$ for at least $4 \mathrm{hrs}$. Thereafter, $400 \mu \mathrm{L}$ propidium iodide (PI, $50 \mu \mathrm{g} / \mathrm{mL})$ and $100 \mu \mathrm{L}$ RNase A $(100 \mu \mathrm{g} / \mathrm{mL})$ were added and cell suspension was incubated at $4{ }^{\circ} \mathrm{C}$ in the dark for 30 mins. Cells were further evaluated by flow cytometry using standard procedures.

\section{Western blotting}

Cells were grouped and treated as previously described. After 48 hours of hirsutine treatment, the cells were lysed for $30 \mathrm{~min}$ in cold RIPA buffer (Beyotime, China). The obtained lysates were spun for $15 \mathrm{~min}$ at $12,000 \mathrm{rpm}$ at $4{ }^{\circ} \mathrm{C}$, and the BCA method (Beyotime, China) was then employed to quantify protein levels in supernatants. Next, $50 \mu \mathrm{g}$ of protein in each sample was separated via SDS-PAGE and transferred to PVDF membranes. At room temperature, blots were blocked using 
157

158

159

160

161

162

163

164

165

166

167

168

169

170

171

172

173

174

175

176

177

178

179

180

181

182

183

184

185

186

187

188

189

190

191

192

193

194

195

$5 \%$ skim milk for $2 \mathrm{~h}$ prior to incubation along with different primary antibodies (1:1,000 dilution) at $4{ }^{\circ} \mathrm{C}$ overnight. Blots were further washed 3 times with 1xTBST, and probed for $1 \mathrm{~h}$ with secondary antibody $(1: 5,000)$ at room temperature. Blots were washed thrice using $1 x T B S T$ again, and the protein bands were visualized with an ECL system (Bio-Rad, China).

\section{QPCR analysis}

Cells at the logarithmic phase were plated into 6-well dish at $10^{6}$ per well, cultured for 48 hours, and then treated with hirsutine at different doses for 48 hours. Total RNA was extracted with TRIpure Regent reagent (Ambion, Thermo-Fisher Scientific,Waltham, USA) and digested by FastKing gDNA with RT SuperMix (Tiangen, Beijing, China) for reverse transcription. The expressions of mRNA of Bax, Bcl-2, cleavage-caspase 3, cleavage-caspase 9, Cyto c and GAPDH were detected by TaqMan probe. QPCR was carried out, in accordance with instruction manual, using ChamQ TM SYBR qPCR Master Mix and Applied Biosystems SDS 7500 instrument (Applied Biosystems Inc., CA, USA). PCR reactions were submitted to the following cycling conditions: $50{ }^{\circ} \mathrm{C}$ for 2 mins, $95{ }^{\circ} \mathrm{C}$ for 10 mins and 40 cycles of $95{ }^{\circ} \mathrm{C}$ for $30 \mathrm{sec}, 60{ }^{\circ} \mathrm{C}$ for $30 \mathrm{sec}$. PCR samples were loaded onto ethidium bromide-containing $2 \%$ agarose gels and analyzed by UV spectrophotometry. Primer sequences were as follows: bax(223bp), F-5GGCCCTTTTGCTTCAGGGTT-3, R-5-AGCTGCCACTCGGAAAAAGA-3, bcl-2(383bp), F5-GACAACATCGCCCTGTGGAT-3, R-5-GACTTCACTTGTGGCCCAGAT-3, caspase3(182bp), F-5-TGGAACCAAAGATCATACATGGAA-3, R-5TTCCCTGAGGTTTGCTGCAT-3, caspase-9(193bp), F-5-AGGCCCCATATGATCGAGGA-3, R-5-TCGACAACTTTGCTGCTTGC-3, gapdh(115bp), F-TCAAGAAGGTGGTGAAGC-AGG, R-TCAAAGGTGGAGGAGTGGGT.

\section{Statistical analysis}

All the above data are means \pm SD of three or more experiments. Differences between groups were compared through ANOVAs and t-tests. $P<0.05$ was the significance threshold.

\section{Results}

\section{Impact of hirsutine on Jurkat Clone E6-1 cell viability}

Firstly, we investigated the impacts of hirsutine on cellular proliferation in human leukemia cells (Jurkat Clone E6-1), normal human THLE-2 hepatocytes and normal human tubular epithelial cells HK2. T-cell leukemia Jurkat Clone E6-1 cells were treated with increasing doses of hirsutine $(3.9,4.7,9.4,18.8,37.5,75,150$ and $300 \mu \mathrm{M})$ for 24,48 and 72 hours, respectively. Normal human THLE-2 hepatocytes and human normal tubular epithelial cells HK2 were treated with a range of hirsutine doses for 48 hours. Exposure of Jurkat Clone E6-1 cells to hirsutine markedly impaired their survival in a dose and time-dependent fashion. Higher drug concentrations, used for a longer time of treatment, resulted in a more pronounced inhibitory effect on cells. In fact, more significant differences were observed at concentrations higher than 
196

197

198

199

200

201

202

203

204

205

206

207

208

209

210

211

212

213

214

215

216

217

218

219

220

221

222

223

224

225

226

227

228

229

230

231

232

233

234

235

$37.5 \mu \mathrm{M}$ (Fig. 2A). However, in case of normal human THLE-2 hepatocytes and normal human tubular epithelial cells HK2, after 48 hours of drug exposure, hirsutine had nearly no influence (Fig. 2B). These data suggest that hirsutine effectively and selectively inhibit Jurkat Clone E6-1 cell proliferation (Fig. 2).

\section{Effect of hirsutine on the apoptosis cell death of Jurkat E6-1 cells}

To examine whether the cytotoxic activity of hirsutine is linked to apoptotic cell death, Jurkat E6-1 cells, were treated with hirsutine and Annexin V-FITC staining assay was performed. As shown in Fig. 3, after 48 hours of treatment with 10, 25 and $50 \mu \mathrm{M}$ hirsutine, the percentage of Annexin V-FITC positive cells increased up to $4.99 \pm 0.51 \%, 13.69 \pm 2.00 \%$ and $40.21 \pm 15.19 \%$ in Jurkat cells, respectively. These results suggest that the cell growth inhibitory effect of hirsutine is linked to apoptotic death in human Jurkat Clone E6-1 cells.

\section{Hirsutine induces G0/G1 phase arrest}

Cell cycle arrest is an additional mechanism that can disrupt the growth of tumor cells (Qiu et al. 2011). In order to explore how hirsutine impacts cellular proliferation, we examined the inhibition of such proliferation was a consequence of cell cycle arrest. Treatment with hirsutine was related to a considerable increase in G0/G1 phase Jurkat cells (Fig. 4). In the control group, normal cells distributed in the G0/G1 period accounted for $20.54 \pm 4.23 \%$ of the total cell population and those of stage $\mathrm{S}$ and $\mathrm{G} 2 / \mathrm{M}$ each accounted for $78.23 \pm 3.13 \%$ and $1.26 \pm 1.20 \%$. However, after treatment with $50 \mu \mathrm{M}$ hirsutine for $48 \mathrm{~h}$, the percentage of cells in $\mathrm{G} 0 / \mathrm{G} 1$ phase rose to $49.12 \pm 4.07 \%$ significantly, and decreased in phase $\mathrm{S}$ and $\mathrm{G} 2 / \mathrm{M}$, which shows each doses have statistically significant, compared with the control $(P<0.05$ or $P<0.01)$ (Fig.4). Overall, our results demonstrate that hirsutine might inhibit cell viability of Jurkat Clone E6-1 cells via inducing G0/G1 phase cell arrest, suggesting that the cell growth inhibition effect of hirsutine was mediated by cell cycle control (Fig. 4).

\section{Hirsutine induces the mitochondrial dysfunction in human Jurkat Clone E6-1 cells}

To elucidate whether hirsutine drives apoptotic death via the induction of the mitochondrial pathway of apoptotic cell death, we quantified changes in Bcl-2 expression and caspase activation. Mitochondrial membrane potential changes can be used to monitor abnormal mitochondrial functionality early during apoptosis. Immunoblotting revealed that Jurkat Clone E6-1 cell treatment with hirsutine increased Bax, cleaved-caspase 3/9 and Cyto c protein levels (Fig. 5A). However, hirsutine was associated with reductions in Bcl-2 expression, resulting in a rise in the Bcl-2 pro-/anti-apoptotic ratio (Fig. 5B-D). Apoptotic progression is characterized by the activation of caspases that control the cell death cascade. Hirsutine enhanced upstream caspase-9 activity in Jurkat Clone E6-1 cells (Fig. 5E). In addition, hirsutine also increased the activation of effector caspase-3 in Jurkat cells (Figs. 5F). Moreover, hirsutine drove mitochondrial Cytochrome $\mathrm{c}$ release into the cytosol in a dose-dependent fashion (Fig. 5G). It is 
236 further confirmed that hirsutine induces apoptosis of human Jurkat clone E6-1 cells by

237

238

239

240

241

242

243

244

245

246

247

248

249

250

251

252

253

254

255

256

257

258

259

260

261

262

263

264

265

266

267

268

269

270

271

272

273

274

275

promoting mitochondrial dysfunction.

\section{Changes on the levels of Bcl-2, Bax, caspase-3 and caspase-9 mRNA}

QPCR analysis showed that, after 48 hours of treatment with different doses of hirsutine, Bax mRNA levels increased, while $B C L 2$ expression decreased. The mRNA levels of caspase-3 and caspase- 9 were also increased in hirsutine-treated Jurkat cells. The concentrations of 10, 25, and $50 \mu \mathrm{M}$ hirsutine were more effective than the untreated group $(p<0.05)$ (Fig. 6).

\section{Discussion}

Research on new chemotherapeutics is inseparable from TCM, because it is still suitable for storage of new molecules (Yun et al. 2012; Zheng et al. 2017). Hirsutine, an indole alkaloid, originally isolated from Uncaria rhynchophylla, has an anti-cancer property, whose efficacy rises relying on the dosage and hours in vivo (Huang et al. 2018; Zhang et al. 2018). Through this experiment, we have confirmed that hirsutine can inhibit the growth of Jurkat Clone E6-1 cells and promote cell death to a certain extent. Specifically, it can stop cell growth in G0/G1 phase, and cause cell death through ajusting caspase activation signaling pathway and cell-cycle regulatory proteins.

The antitumor activity of hirsutine has been well reported (Huang et al. 2018; Zhang et al. 2018). First, we evaluated the effects of hirsutine on the proliferation of human leukemia cells (Jurkat Clone E6-1), normal human THLE-2 hepatocytes and normal human tubular epithelial cells HK2 cells. After administration, different incubation time corresponds to different cell proliferation cycle numbers, and the determination of action time is related to the growth cycle of tumor cells. The reason why the drug acts on cells for 48 hours also depends on the number of cells at that time. Cells enter the exponential growth stage after 12-24 hours of passage, and enter the plateau stage 48-72 hours after passage generally. At this time, the administration effect is the most obvious and typical. T-cell leukemia Jurkat Clone E6-1 cells were dealed with increasing dosages of hirsutine for 24, 48 and 72 hours, respectively. Normal human THLE-2 hepatocytes and normal human tubular epithelial cells HK2 were dealed with various dosages of hirsutine for $48 \mathrm{hrs}$. After treated with hirsutine, the cell viability of Jurkat clone E6-1 cells decreased significantly under conditions of different concentrations and hours (Fig. 2). However, despite being treated with hirsutine for 48 hours, THLE-2 hepatocytes and normal human renal tubular epithelial cells HK2 (Fig. 2A, B) were almost not been inhibited. These data suggest that hirsutine has a selectively inhibitory effect on the growth of Jurkat cells.

Mitochondria are closely linked to apoptotic induction, and proteins in the Bcl-2 family regulate the function of these organelles, including both pro-apoptotic Bax and anti-apoptotic Bcl-2 (Adams \& Cory 2007; Hengartner 2000). In this study, the increased expression of Bax and Cyt $\mathrm{c}$ indicated that hirsutine $(10,25$, and $50 \mu \mathrm{mol} / \mathrm{L})$ can promote the release of Cyt $\mathrm{c}$ from mitochondria, thereby inducing the initiation of mitochondrial-mediated pathways. As an antiapoptotic protein, bcl-2 can prevent the release of Cyt c from mitochondria (Liu et al. 2013).

Peer) reviewing PDF | (2020:05:49102:3:0:NEW 6 Dec 2020) 
276 Some studies have shown that hirsutine induces apoptosis by down-regulating the expression of 277 Bcl-2 (Huang et al. 2018; Zhang et al. 2018). In this study, we focused on the mitochondrial278 dependent pathway to cell death. The up-regulation of BCL2 levels may be the compensatory 279 protective effect of hirsutine on Jurkat Clone E6-1 cell apoptosis at concentrations of 10, 25 and $28050 \mu \mathrm{mol} / \mathrm{L}$. Hirsutine treatment led to marked reductions in Bcl-2 expression and enhanced Bax 281 expression, suggesting that this shift in the Bax/Bcl-2 ratio may govern the apoptotic function of 282 hirsutine. Moreover, pro-apoptotic Bax can form pores in the mitochondrial membrane and 283 facilitate cytochrome $\mathrm{c}$ release (Antonsson et al. 1997). The cells released into the cytoplasm can 284 promote the binding of Apaf-1 and caspase-9 and promote the activation of caspase-9 (Brentnall 285 et al. 2013; Kole et al. 2011). Caspase family is an important class of proteases typically

286

287

288

289

290

291

292

293

294

295

296

297

298

299

300

301

302

303

304

305

306

307

308

309

310

311

312

\section{Conclusions}

314

315 involved in the apoptosis pathway. Caspase-3, as a key factor in the execution of apoptosis, can be activated by activated capsase- 9 (Thomas et al. 2017). Previous studies reported that hirsutine induces apoptosis by activating caspase-9 and caspase-3 (Huang et al. 2018; Zhang et al. 2018). In this study, the increased expression of Caspase- 3 and Caspase-9 indicated that Caspase- 3 and Caspase- 9 caused the caspase cascade, which led to cell death. In short, excessive hirsutine can destroy the ultrastructure of mitochondrial cells, leading to the release of mitochondrial Cytc and the initiation of mitochondrial pathways. In addition, Cyt $\mathrm{c}$ may activate the downstream cascade of caspases. Generally, excessive hirsutine can induce apoptosis of Jurkat Clone E6-1 cells through a mitochondrial-mediated pathway.

Inducing cell cycle arrest is a primary antitumor treatment strategy (Asci Celik et al. 2020). Therefore, elucidating the way in which hirsutine inhibits cell cycle progression may provide a mechanism basis for the anticancer effects of these herbs. Although previous studies have shown that it is difficult to determine the target of hirsutine, this study shows that hirsutine blocks the cell cycle in $\mathrm{G} 0 / \mathrm{G} 1$ phase, that is to say, it blocks the cell cycle at the early stage of DNA synthesis, prevents the synthesis of RNA and protein at this stage, and prevents the cell cycle from entering the $\mathrm{S}$ phase. The results showed that hirsutine blocked tumor cell proliferation via inducing $\mathrm{G} 0 / \mathrm{G} 1$ phase arrest.

Bcl-2 family proteins are regulatory factors of apoptosis. Many pro-apoptotic members of this family, such as Bax and Bak, govern caspase-mediated cell death pathway. The ratio of Bcl2/Bax protein may explain the protective mechanism of Bcl-2 protein in cells. Our results indicate that hirsutine disrupts the balance of pro- and anti-apoptotic proteins in the Bcl-2 family, leading to the destruction of mitochondrial membrane and intrinsic pathway mediated apoptosis. QPCR analyses were further performed to evaluate mRNA levels of Bax, Bcl-2, caspase-3 and caspase-9. As previously indicated, hirsutine could diminish Bcl-2 mRNA levels and, at the same time, improve Bax, caspase- 3 and caspase- 9 mRNA content, thus increasing the ratio of proversus anti-apoptotic proteins.

In the present work, we show that an important bioactive component isolated from Uncaria rhynchophylla - hirsutine - had inhibitory effect on Jurkat Clone E6-1 cells, because it can 
316 promote cell proliferation in the G0/G1 phase, and inhibit cell growth in the $\mathrm{S}$ and $\mathrm{G} 2 / \mathrm{M}$ phase,

317 promoting cell death upon elevating Bax, cleaved-caspase 3/9 and Cyto c proteins but decreasing

318 the yields of Bcl-2 protein. At the same time, hirsutine treatment also elevated caspase- 3 and

319 caspase-9 mRNA levels, suggesting that hirsutine has a potential antitumor activity, thus

320 enlightening the use of phytomedicines in tumor therapy.

321 In summary, the research has profoundly investigated the antitumor effects of hirsutine,

322 showing its possible effects on treating T-cell leukemia. More in-depth studies will be badly

323 needed to explore more precise mechanisms related to the hirsutine-mediated antitumor activity.

324

325 Acknowledgements

326 The authors thank the reviewers for their helpful comments on this report.

327

328

\section{Conflicts of Interest}

329

330

331

332

333

334

335

336

337

338

339

The authors declare that there are no conflicts of interest.

\section{Author Contributions}

- Jie Meng conceived and designed the experiments, performed the experiments, analyzed the data, prepared figures and/or tables, authored or reviewed drafts of the paper, and approved the final draft.

- Rui Su conceived and designed the experiments, analyzed the data, authored or reviewed drafts of the paper, and approved the final draft.

- Luping Wang analyzed the data, authored or reviewed drafts of the paper.

- Bo Yuan analyzed the data, authored or reviewed drafts of the paper, and approved the final draft.

340

- Ling Li conceived and designed the experiments, authored or reviewed drafts of the paper, and approved the final draft.

\section{Data Availability Statement}

344 The following information was supplied regarding data availability:

345 The raw data is supplied as Supplemental Information.

346

347

\section{Funding}

348 This research did not receive any specific grant from funding agencies of the public, commercial, or not-for-profit sectors.

350

351

352

353

\section{References}

Adams JM, and Cory S. 2007. The Bcl-2 apoptotic switch in cancer development and therapy. 
354

355

356

357

358

359

360

361

362

363

364

365

366

367

368

369

370

371

372

373

374

375

376

377

378

379

380

381

382

383

384

385

386

387

388

389

390

391

392

393

Oncogene 26:1324-1337. 10.1038/sj.onc. 1210220

Almodovar T, Teixeira E, Barroso A, Soares M, Queiroga HJ, Cavaco-Silva J, and Barata F. 2019. Elderly patients with advanced NSCLC: The value of geriatric evaluation and the feasibility of CGA alternatives in predicting chemotherapy toxicity. Pulmonology 25:4050. 10.1016/j.pulmoe.2018.07.004

Antonsson B, Conti F, Ciavatta A, Montessuit S, Lewis S, Martinou I, Bernasconi L, Bernard A, Mermod JJ, Mazzei G, Maundrell K, Gambale F, Sadoul R, and Martinou JC. 1997. Inhibition of Bax channel-forming activity by Bcl-2. Science 277:370-372. 10.1126/science. 277.5324 .370

Asci Celik D, Gurbuz N, Togay VA, and Ozcelik N. 2020. Ochratoxin A causes cell cycle arrest in G1 and G1/S phases through p53 in HK-2 cells. Toxicon 180:11-17. 10.1016/j.toxicon.2020.03.012

Bray F, Ferlay J, Soerjomataram I, Siegel RL, Torre LA, and Jemal A. 2018. Global cancer statistics 2018: GLOBOCAN estimates of incidence and mortality worldwide for 36 cancers in 185 countries. CA Cancer J Clin 68:394-424. 10.3322/caac.21492

Brentnall M, Rodriguez-Menocal L, De Guevara RL, Cepero E, and Boise LH. 2013. Caspase-9, caspase-3 and caspase-7 have distinct roles during intrinsic apoptosis. BMC Cell Biol 14:32. 10.1186/1471-2121-14-32

Child GBD, Adolescent Health C, Reiner RC, Jr., Olsen HE, Ikeda CT, Echko MM, Ballestreros KE, Manguerra H, Martopullo I, Millear A, Shields C, Smith A, Strub B, Abebe M, Abebe Z, Adhena BM, Adhikari TB, Akibu M, Al-Raddadi RM, Alvis-Guzman N, Antonio CAT, Aremu O, Asgedom SW, Asseffa NA, Avila-Burgos L, Barac A, Barnighausen TW, Bassat Q, Bensenor IM, Bhutta ZA, Bijani A, Bililign N, Cahuana-Hurtado L, Malta DC, Chang JC, Charlson FJ, Dharmaratne SD, Doku DT, Edessa D, El-Khatib Z, Erskine HE, Ferrari AJ, Fullman N, Gupta R, Hassen HY, Hay SI, Ilesanmi OS, Jacobsen KH, Kahsay A, Kasaeian A, Kassa TD, Kebede S, Khader YS, Khan EA, Khan MN, Khang YH, Khubchandani J, Kinfu Y, Kochhar S, Kokubo Y, Koyanagi A, Defo BK, Lal DK, Kumsa FA, Larson HJ, Leung J, Mamun AA, Mehata S, Melku M, Mendoza W, Mezgebe HB, Miller TR, Moges NA, Mohammed S, Mokdad AH, Monasta L, Neupane S, Nguyen HLT, Ningrum DNA, Nirayo YL, Nong VM, Ogbo FA, Olagunju AT, Olusanya BO, Olusanya JO, Patton GC, Pereira DM, Pourmalek F, Qorbani M, Rafay A, Rai RK, Ram U, Ranabhat CL, Renzaho AMN, Rezai MS, Ronfani L, Roth GA, Safiri S, Sartorius B, Scott JG, Shackelford KA, Sliwa K, Sreeramareddy C, Sufiyan MB, Terkawi AS, Topor-Madry R, Tran BX, Ukwaja KN, Uthman OA, Vollset SE, Weldegwergs KG, Werdecker A, Whiteford HA, Wijeratne T, Yonemoto N, Yotebieng M, Zuhlke LJ, Kyu HH, Naghavi M, Vos T, Murray CJL, and Kassebaum NJ. 2019. Diseases, Injuries, and Risk Factors in Child and Adolescent Health, 1990 to 2017: Findings From the Global Burden of Diseases, Injuries, and Risk Factors 2017 Study. JAMA Pediatr 173:e190337. 10.1001/jamapediatrics.2019.0337

Chirumbolo S. 2012. Plant phytochemicals as new potential drugs for immune disorders and 
394

395

396

397

398

399

400

401

402

403

404

405

406

407

408

409

410

411

412

413

414

415

416

417

418

419

420

421

422

423

424

425

426

427

428

429

430

431

432

433

cancer therapy: really a promising path? J Sci Food Agric 92:1573-1577. 10.1002/jsfa.5670 Crowell JA. 2005. The chemopreventive agent development research program in the Division of Cancer Prevention of the US National Cancer Institute: an overview. Eur J Cancer 41:1889-1910. 10.1016/j.ejca.2005.04.016

Foerster B, Pozo C, Abufaraj M, Mari A, Kimura S, D'Andrea D, John H, and Shariat SF. 2018. Association of Smoking Status With Recurrence, Metastasis, and Mortality Among Patients With Localized Prostate Cancer Undergoing Prostatectomy or Radiotherapy: A Systematic Review and Meta-analysis. JAMA Oncol 4:953-961. 10.1001/jamaoncol.2018.1071

Hengartner MO. 2000. The biochemistry of apoptosis. Nature 407:770-776. 10.1038/35037710

Horie S, Yano S, Aimi N, Sakai S, and Watanabe K. 1992. Effects of hirsutine, an antihypertensive indole alkaloid from Uncaria rhynchophylla, on intracellular calcium in rat thoracic aorta. Life Sci 50:491-498. 10.1016/0024-3205(92)90388-6

Huang QW, Zhai NN, Huang T, and Li DM. 2018. [Hirsutine induces apoptosis of human breast cancer MDA-MB-231 cells through mitochondrial pathway]. Sheng Li Xue Bao 70:40-46.

Hung KF, Hsu CP, Chiang JH, Lin HJ, Kuo YT, Sun MF, and Yen HR. 2017. Complementary Chinese herbal medicine therapy improves survival of patients with gastric cancer in Taiwan: A nationwide retrospective matched-cohort study. J Ethnopharmacol 199:168174. 10.1016/j.jep.2017.02.004

Jung HY, Nam KN, Woo BC, Kim KP, Kim SO, and Lee EH. 2013. Hirsutine, an indole alkaloid of Uncaria rhynchophylla, inhibits inflammation-mediated neurotoxicity and microglial activation. Mol Med Rep 7:154-158. 10.3892/mmr.2012.1135

Kole AJ, Knight ER, and Deshmukh M. 2011. Activation of apoptosis by cytoplasmic microinjection of cytochrome c. J Vis Exp. 10.3791/2773

Li B, Wang C, Cheng A, Kim K, Liu H, Li M, Mao M, Han Z, and Feng Z. 2019. Modified incontinuity resection is advantageous for prognosis and as a new surgical strategy for management of oral tongue cancer. Oral Surg Oral Med Oral Pathol Oral Radiol. 10.1016/j.oooo.2019.09.016

Liu J, Cui H, Peng X, Fang J, Zuo Z, Wang H, Wu B, Deng Y, and Wang K. 2013. Dietary high fluorine induces apoptosis and alters Bcl-2, Bax, and caspase-3 protein expression in the cecal tonsil lymphocytes of broilers. Biol Trace Elem Res 152:25-30. 10.1007/s12011-0129595-2

Lou C, Takahashi K, Irimura T, Saiki I, and Hayakawa Y. 2014. Identification of Hirsutine as an anti-metastatic phytochemical by targeting NF-kappaB activation. Int J Oncol 45:20852091. 10.3892/ijo.2014.2624

Lou C, Yokoyama S, Saiki I, and Hayakawa Y. 2015. Selective anticancer activity of hirsutine against HER2positive breast cancer cells by inducing DNA damage. Oncol Rep 33:20722076. 10.3892/or.2015.3796

Miller KD, Nogueira L, Mariotto AB, Rowland JH, Yabroff KR, Alfano CM, Jemal A, Kramer JL, and Siegel RL. 2019. Cancer treatment and survivorship statistics, 2019. CA Cancer J 
434

435

436

437

438

439

440

441

442

443

444

445

446

447

448

449

450

451

452

453

454

455

456

457

458

459

460

461

462

463

464

465

466

467

Clin 69:363-385. 10.3322/caac.21565

Mondini M, Levy A, Meziani L, Milliat F, and Deutsch E. 2020. Radiotherapy-immunotherapy combinations: perspectives and challenges. Mol Oncol. 10.1002/1878-0261.12658

Nunez C, Clausen J, Jensen MT, Holtermann A, Gyntelberg F, and Bauman A. 2018. Main and interactive effects of physical activity, fitness and body mass in the prevention of cancer from the Copenhagen Male Study. Sci Rep 8:11780. 10.1038/s41598-018-30280-5

Qiu P, Guan H, Dong P, Li S, Ho CT, Pan MH, McClements DJ, and Xiao H. 2011. The p53-, Bax- and p21-dependent inhibition of colon cancer cell growth by 5-hydroxy polymethoxyflavones. Mol Nutr Food Res 55:613-622. 10.1002/mnfr.201000269

Thomas CN, Berry M, Logan A, Blanch RJ, and Ahmed Z. 2017. Caspases in retinal ganglion cell death and axon regeneration. Cell Death Discov 3:17032. 10.1038/cddiscovery.2017.32

Uramova S, Kubatka P, Dankova Z, Kapinova A, Zolakova B, Samec M, Zubor P, Zulli A, Valentova V, Kwon TK, Solar P, Kello M, Kajo K, Busselberg D, Pec M, and Danko J. 2018. Plant natural modulators in breast cancer prevention: status quo and future perspectives reinforced by predictive, preventive, and personalized medical approach. EPMA J 9:403-419. 10.1007/s13167-018-0154-6

Wu LX, Gu XF, Zhu YC, and Zhu YZ. 2011. Protective effects of novel single compound, Hirsutine on hypoxic neonatal rat cardiomyocytes. Eur $J$ Pharmacol 650:290-297. 10.1016/j.ejphar.2010.09.057

Yancik R, and Ries LA. 2004. Cancer in older persons: an international issue in an aging world. Semin Oncol 31:128-136. 10.1053/j.seminoncol.2003.12.024

Yun J, Lv YG, Yao Q, Wang L, Li YP, and Yi J. 2012. Wortmannin inhibits proliferation and induces apoptosis of MCF-7 breast cancer cells. Eur J Gynaecol Oncol 33:367-369.

Zhang R, Li G, Zhang Q, Tang Q, Huang J, Hu C, Liu Y, Wang Q, Liu W, Gao N, and Zhou S. 2018. Hirsutine induces mPTP-dependent apoptosis through ROCK1/PTEN/PI3K/GSK3beta pathway in human lung cancer cells. Cell Death Dis 9:598. 10.1038/s41419-018-0641-7

Zheng T, Que Z, Jiao L, Kang Y, Gong Y, Yao J, Ma C, Bi L, Dong Q, Zhao X, and Xu L. 2017. Herbal formula YYJD inhibits tumor growth by inducing cell cycle arrest and senescence in lung cancer. Sci Rep 7:4984. 10.1038/s41598-017-05146-X

Zhu K, Yang SN, Ma FF, Gu XF, Zhu YC, and Zhu YZ. 2015. The novel analogue of hirsutine as an anti-hypertension and vasodilatary agent both in vitro and in vivo. PLoS One 10:e0119477. 10.1371/journal.pone.0119477

Peer) reviewing PDF | (2020:05:49102:3:0:NEW 6 Dec 2020) 
Figure 1

Chemical structure of hirsutine $(M W=368.47)$

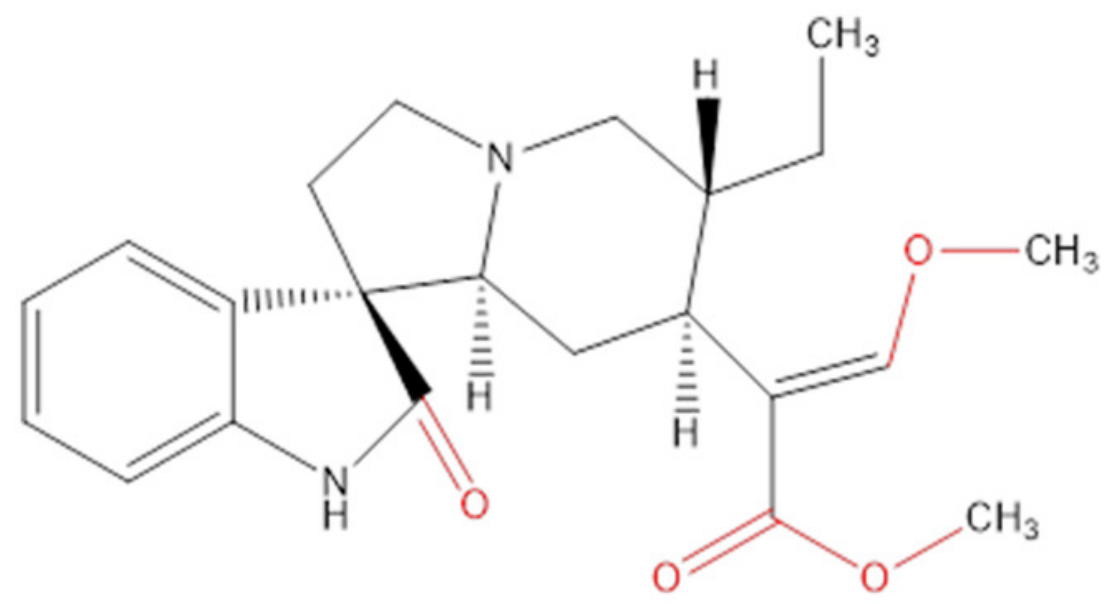




\section{Figure 2}

Effect of hirsutine on Jurkat Clone E6-1 cell growth.

(A) Hirsutine inhibited human Jurkat Clone E6-1 cell line in vitro. Jurkat Clone E6-1 cell lines were treated with different doses of hirsutine for $24,48,72 \mathrm{~h}$. Cell proliferation was determined using a CCK8 assay, $* p<0.05, * * p<0.01$, (B) Effect of hirsutine on normal cells survival. Cells were treated with different doses of hirsutine for $48 \mathrm{~h}$. Cell survival was determined by CCK8 assay, $* p<0.05, * * p<0.01$. 
Jurkat E6-1 cell
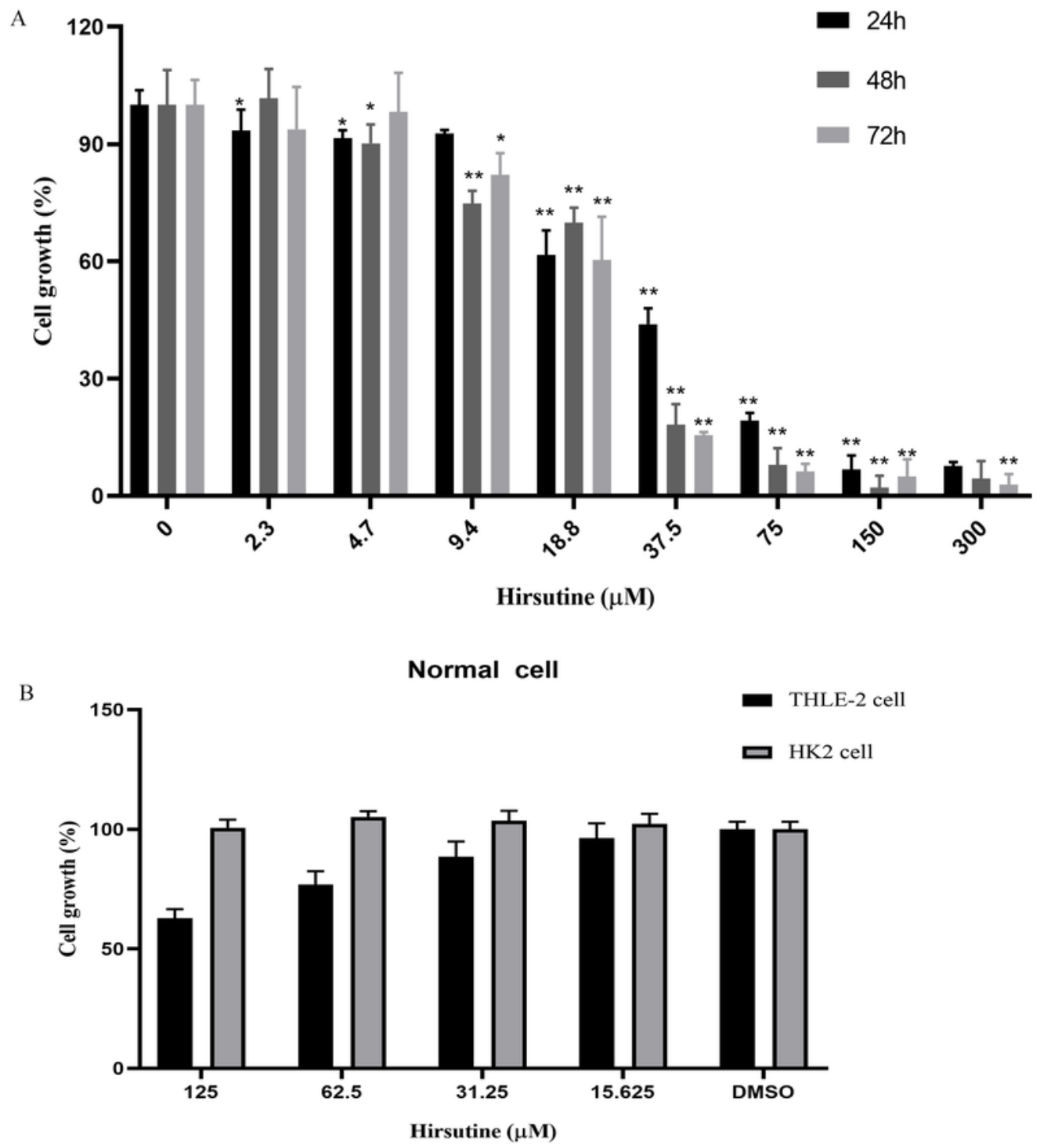
Figure 3

Apoptosis of Jurkat Clone E6-1 cells after treatment with different doses of hirsutine. Jurkat Clone E6-1 cells were treated with different doses of hirsutine for $48 \mathrm{~h}$ and measured by flow cytometry.

(A) control, (B) $10 \mu \mathrm{M}$, (C) $25 \mu \mathrm{M}$, (D) $50 \mu \mathrm{M}$, (E) histogram of apoptosis of Jurkat Clone E6-1 cells, $* p<0.05, * * p<0.01(\mathrm{n}=3)$. 

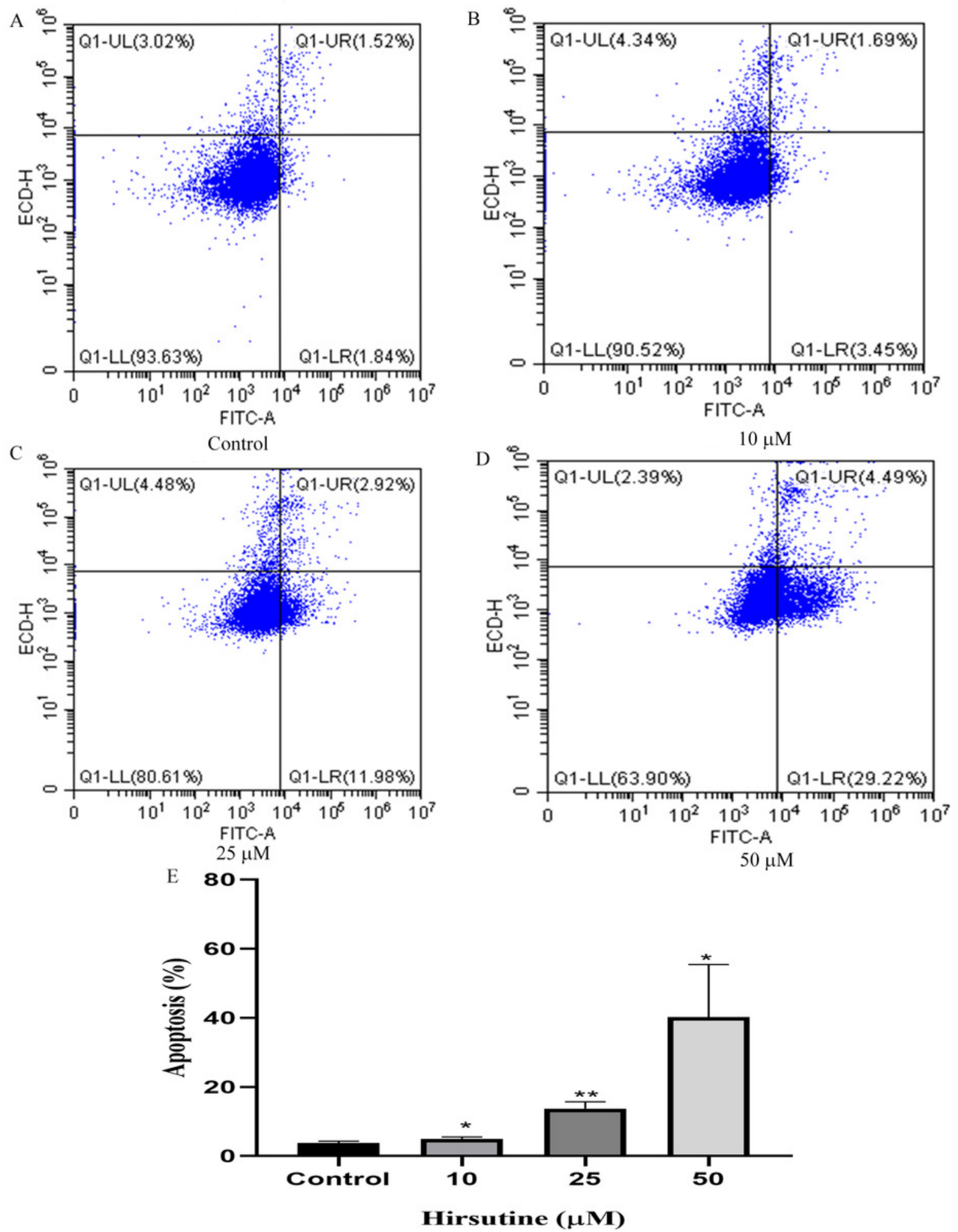
Figure 4

Cell cycle of Jurkat Clone E6-1 cells after treatment with different doses of hirsutine. Jurkat Clone E6-1 cells were treated with different doses of hirsutine for $48 \mathrm{~h}$ and the cell cycle were measured by flow cytometry.

(A) control, (B) $10 \mu \mathrm{M},(C) 25 \mu \mathrm{M}$,(D) $50 \mu \mathrm{M}$, (E) histogram of cell cycle of Jurkat Clone E6-1 cells, $* p<0.05, * * p<0.01(\mathrm{n}=3)$. 

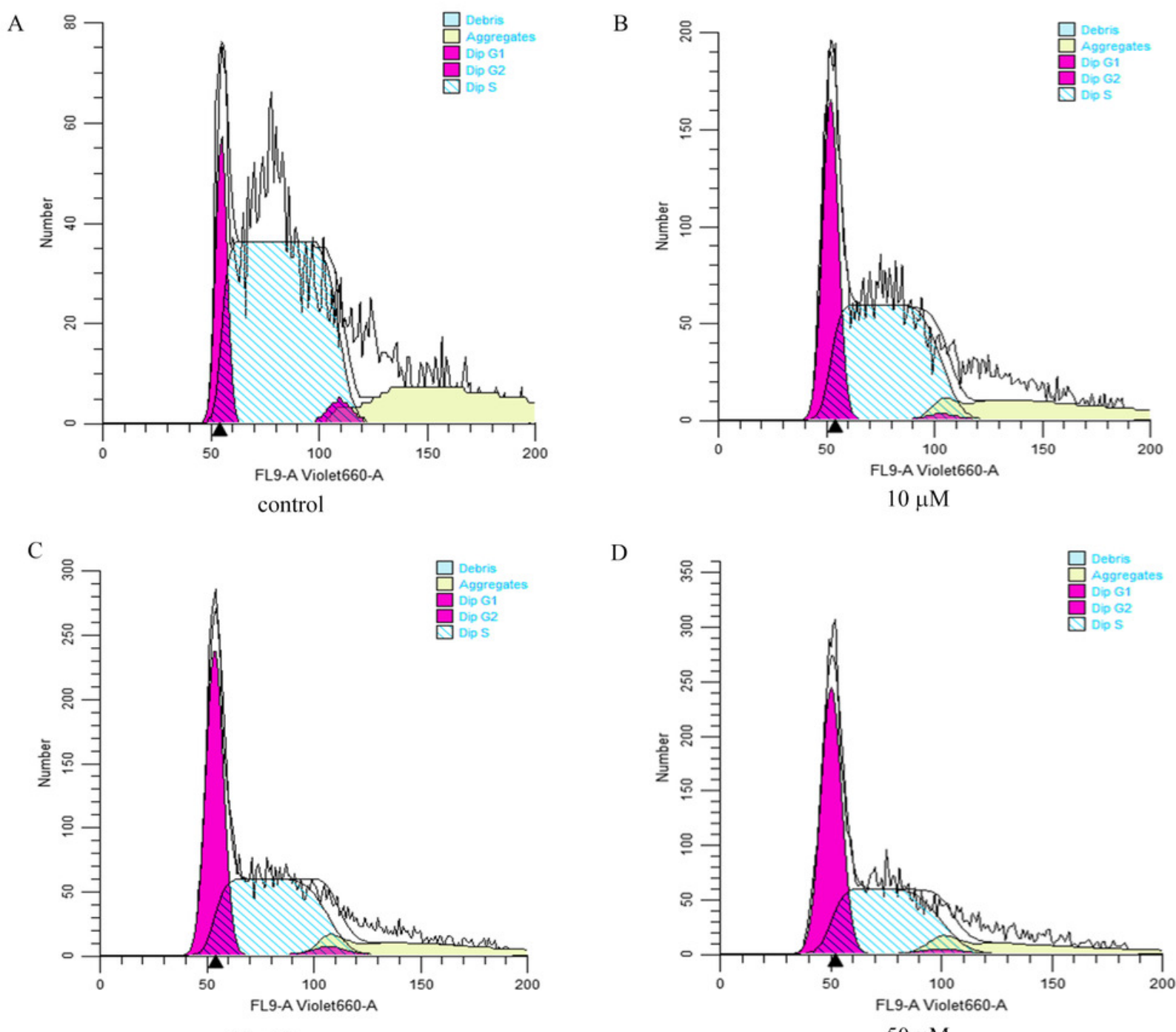

D
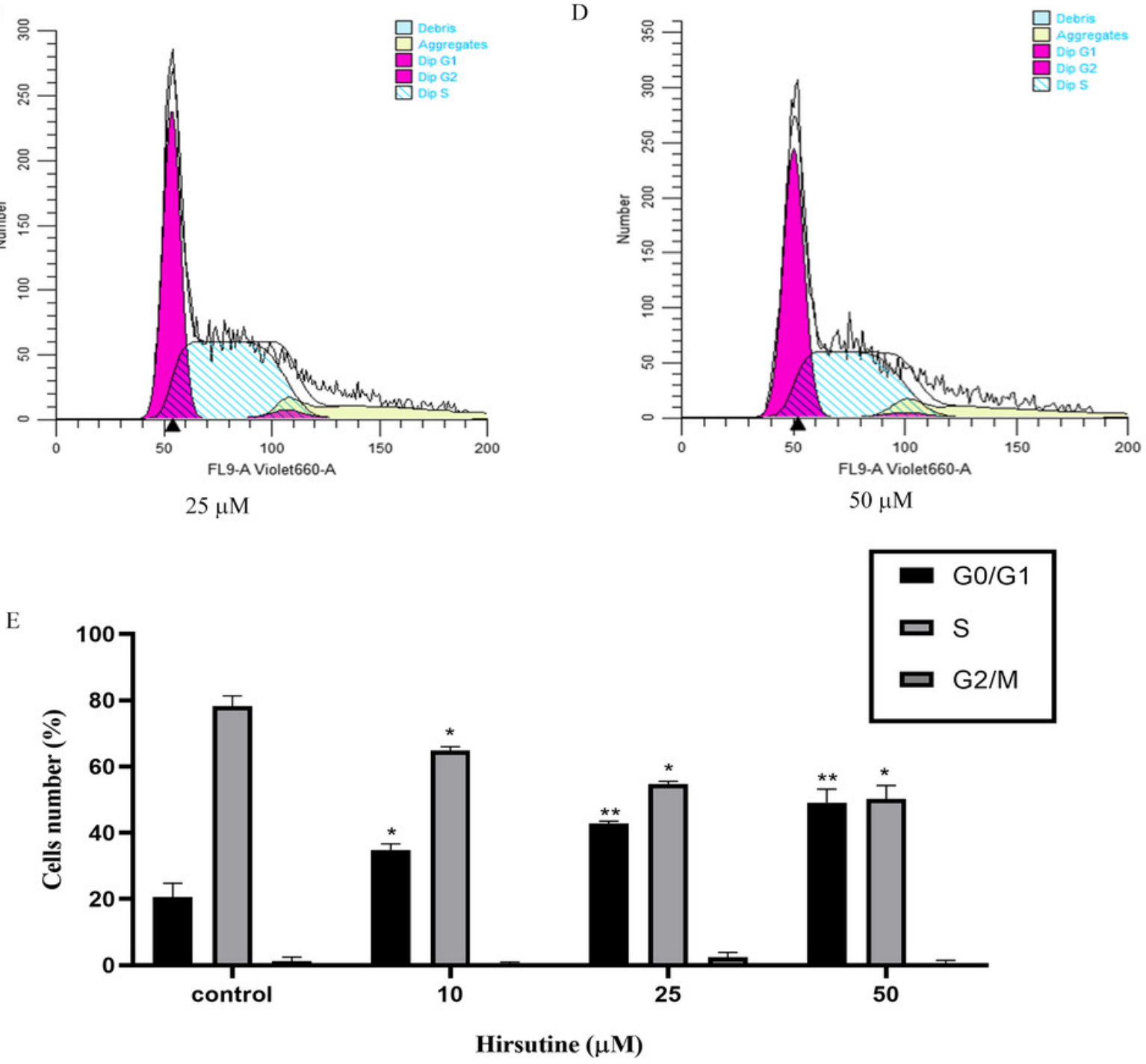


\section{Figure 5}

Effects of hirsutine on $\mathrm{Bcl}-2$ family proteins, and caspase activation proteins in Jurkat Clone E6-1 cells.

After $48 \mathrm{~h}$ treatment by different doses of hirsutine, the bax, bcl-2, cleaved-caspase-3 (C-

Caspase 3), cleaved-caspase-9 (C-Caspas 9) and cytochrome c (Cyto c) in the Jurkat Clone E6-1 cells were measured by western blotting. (A) Total cellular extracts and cytosolic fractions were analyzed by western blot analysis using antibodies against Bax, Bcl-2, cleaved-caspase-3 (C-Caspase 3), cleaved-caspase-9 (C-Caspase 9), and cytochrome c (Cyto C), (B) bax protein content of Jurkat Clone E6-1 cells in different doses of hirsutine, (C) bcl-2 protein content of Jurkat Clone E6-1 cells in different doses of hirsutine, (D) histogram of bax/bcl-2 ratio, (E) cleaved-caspase-9 (C-Caspase 9) protein content of Jurkat Clone E6-1 cells in different doses of hirsutine, (F) cleaved-caspase-3 (C-Caspase 3) protein content of Jurkat Clone E6-1 cells in different doses of hirsutine, (G) cytochrome c (Cyto c) protein content of Jurkat Clone E6-1 cells in different doses of hirsutine, $* p<0.05$, $* * p<0.01(n=3)$. 
A

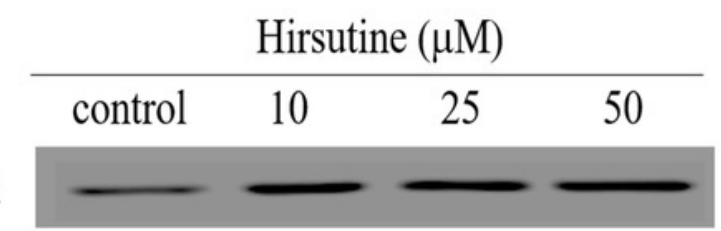

Bcl-2

C-caspase-3

C-caspase-9

$\beta-\operatorname{actin}$

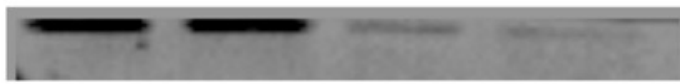

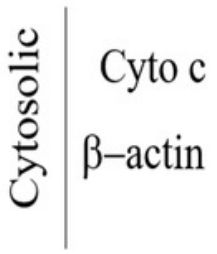

D

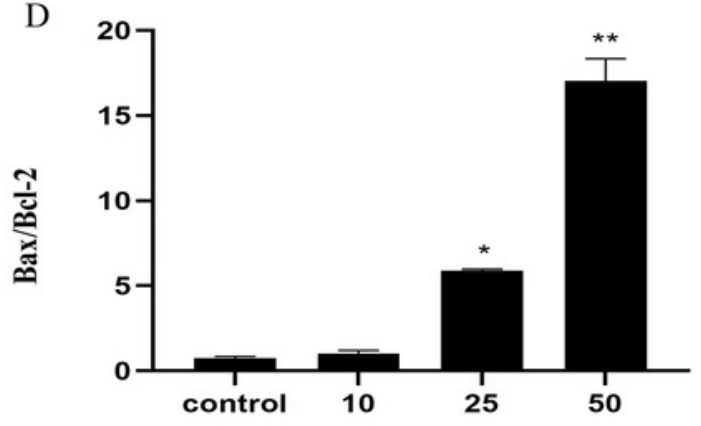

Hirsutine $(\mu \mathrm{M})$

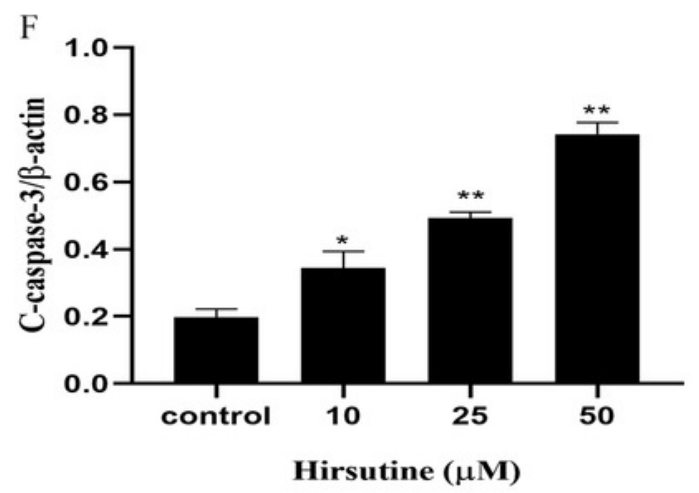

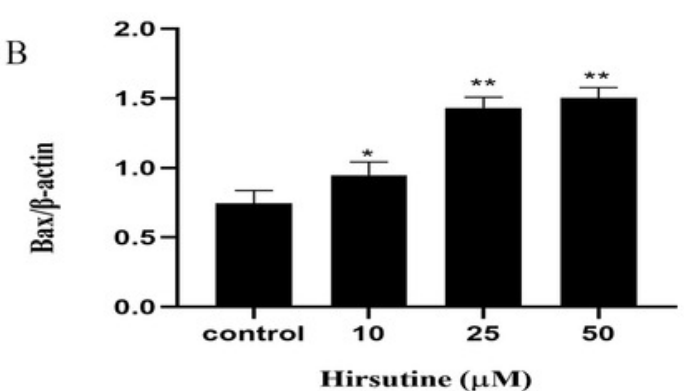
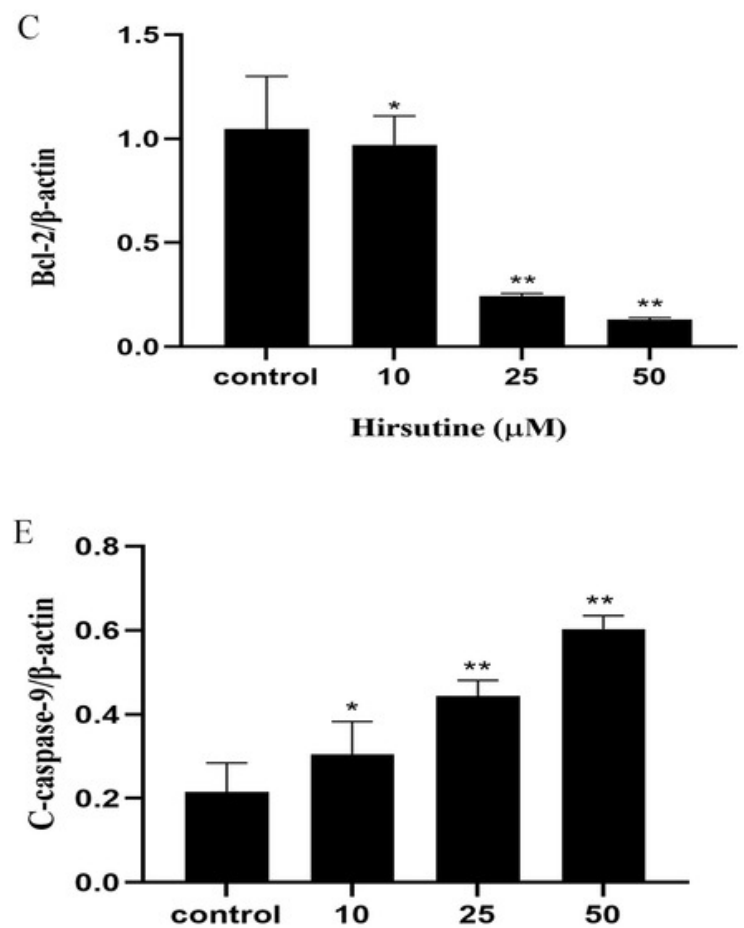

G

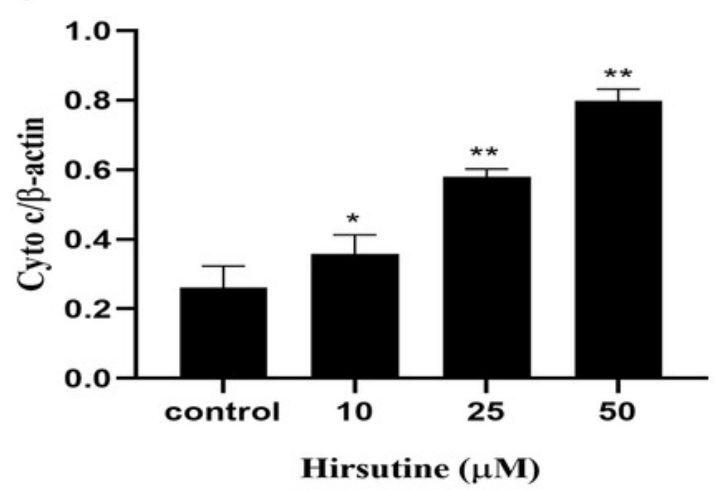


Figure 6

The bax/bcl2, caspase-3/9 mRNA in Jurkat Clone E6-1 cells after treatment with different doses of hirsutine. After $48 \mathrm{~h}$ treatment by different doses of hirsutine, bax/bcl2, caspase-3/9 mRNA in the Jurkat Clone E6-1 cells were measured by qPCR.

(A) histogram of bax, (B) histogram of bcl-2, (C) histogram of caspase-3, (D) histogram of caspase- $9, * p<0.05, * * p<0.01(\mathrm{n}=3)$. 


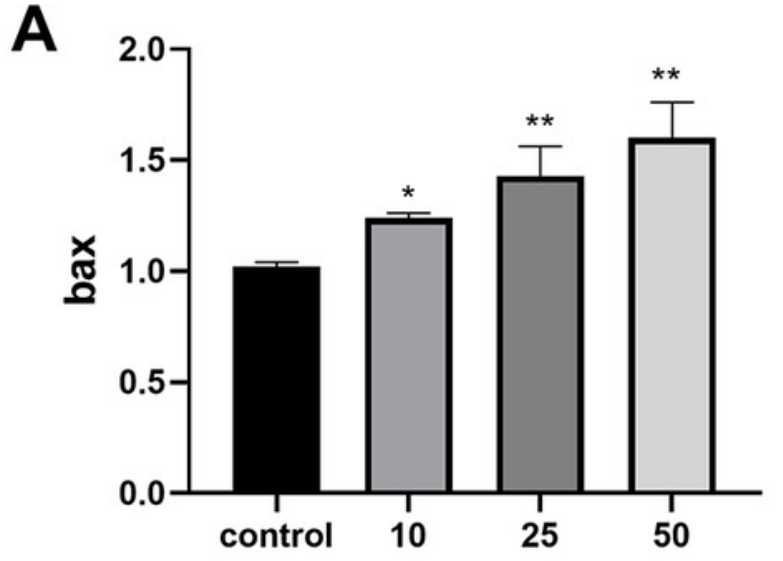

Hirsutine $(\mu \mathrm{M})$

C

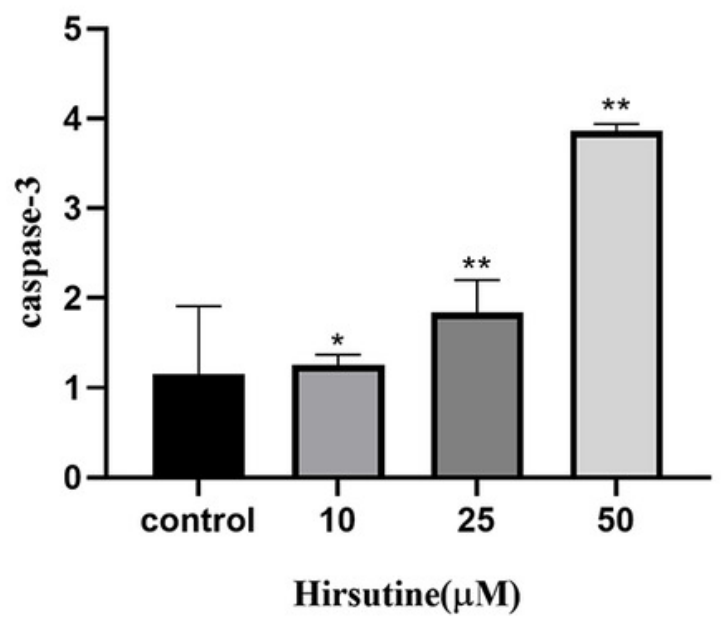

B

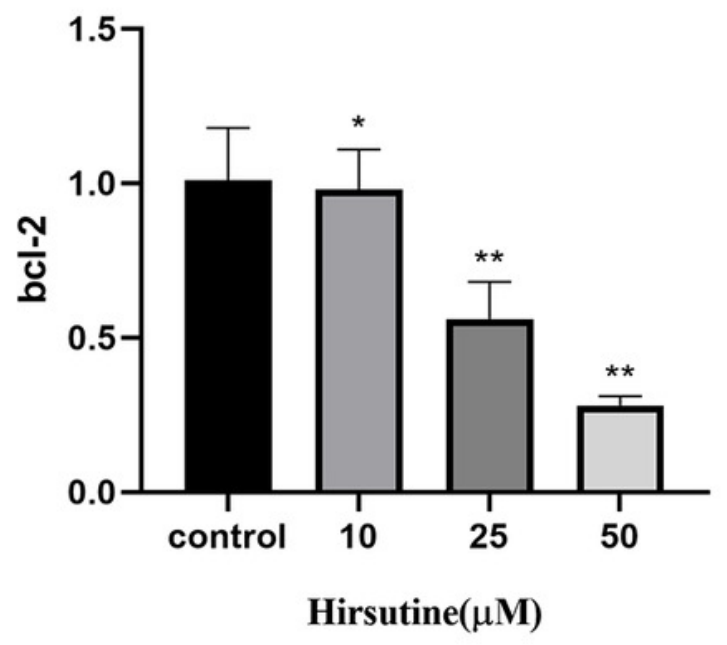

D

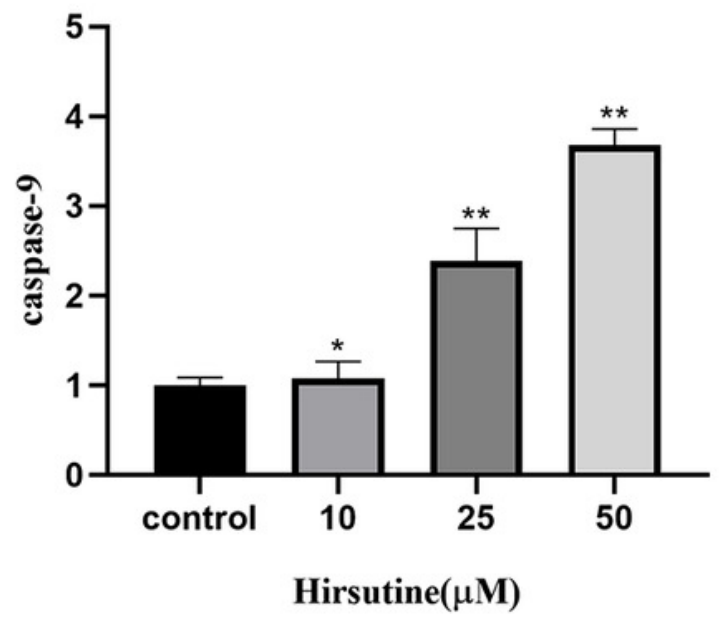

